\title{
The Effect of GIR on Motivation, Vocabulary Mastery, and Reading Comprehension Ability
}

\author{
Rochana Purba Nurfauzi, \\ SMPN 1 Bantarsari-Cilacap, \\ prabunibras@gmail.com
}

\author{
Joko Priyana, Ph.D. \\ Universitas Negeri Yogyakarta \\ j_priyana@yahoo.com
}

\begin{abstract}
This research aims to: (1) describe the effect of GIR as a part of extensive reading; (2) compare the effectiveness between GIR and conventional learning; and (3) compare the effectiveness between GIR variation 1 and 2 on motivation, vocabulary knowledge and reading comprehension ability. The data were analyzed using: (1) the one sample t-test to investigate the effect of GIR; (2) the Helmert Contrast to investigate the difference in the effectiveness of GIR as well as the conventional technique; (3) the post-hoc test involving the Tukey to analyze which was more effective between GIR and conventional technique in students' motivation, vocabulary knowledge and reading comprehension ability. The results of the study show that: (1) GIR has a significant effect on all dependent variables; (2) GIR is more effective than the control group in improving all dependent variables, except GIR variation 1 in reading comprehension ability has equal effect with conventional technique; (3) there is no difference in the effectiveness of GIR variation 1 and 2 in terms of improving students' motivation, vocabulary knowledge, and reading comprehension skills.
\end{abstract}

Keywords: GIR, extensive reading, motivation, vocabulary knowledge, reading comprehension ability

\section{Introduction}

English has been the first foreign language should be taught at school since 1967. But learning the four skills at the same time is very difficult. Nuttall (1996) says that living in the English-speaking countries is the most effective way to gain the language competence. However, this is not possible for the majority of Indonesian learners. Reading offers a crucial opportunity to improve our general language skills in English (Day et al., 1998; Mikulecky \& Jeffries, 1996). 
SMPN 1 Bantarsari-Cilacap belongs to a rural area- school which has various student backgrounds. The students didn't think that English is important except for UN. They study English only at school, and didn't have any intention in reading although they knew that reading is important. They learn English by translating sentences or paragraphs into Indonesian as a means of checking comprehension. Teachers' explanation for these points is also in Indonesian. So, students have a lot of questions, but less curiosity about the materials.

Seeing the problem in teaching English in SMPN 1 Bantarsari-Cilacap, I believe that extensive reading (ER) is an effective solution. As Day (1998) says that the ER activities have positive contribution to motivation and in all aspects of English skills. When students develop the habit of reading, they will get not only fluency in reading, but also an increase in their vocabulary mastery to apply in their speaking, listening, and also writing skills (Day et al., 1998).

Most of the reading activities are in the classroom, and the text is short. The skills taught were looking at main ideas; identifying words; understanding what is implied; and making inferences. The discussion is about the linguistic and contents of the text, which make students feel bored. They do not have independencies on choosing a text to read. To make it clearly, thus activities called a conventional technique. Guided Independent Reading (GIR) is served to cover the boredom situation in conventional technique. GIR as a part of ER is believed can improve their motivation and other skills in reading.

Guided Independent Reading (GIR) is one of variation of extensive reading activities designed by Hsui (2000). The primary object is to develop a community of readers who share the pleasure of reading, motivate one another and interact with fellow readers in discussing the texts read. GIR has two variations of activities: (1) Individual and partnership reading and interaction, and (2) Whole class reading interaction.

GIR as a part of ER methods offers a lot of benefit. It is guided before reading, while reading and after reading. Teachers guide the students in selecting of a text based on placement test; introduce the graded reader books, leaves some problem-solving for readers to do; and guides the discussion after reading.

GIR is independent not only in allowing students to pick a graded level book and read, but also in considering about choice, strategies, time, and goals. The books are available not only at their level, but also below and above their level. They are free to choose it. They are also free to choose strategies when reading and free to read the book at any time. And the last independent meaning in GIR is independent on the goals in reading. Different students may have different goals. It is teacher's job to facilitate their goals in reading.

In addition, affective variables such as motivation, self-confidence, and anxiety are also related to success in second language acquisition (Krashen, 1981). Reading attitudes of students at junior high school are moving from learning to read to reading to learn. They also still in process to develop their vocabulary and knowledge. They like to find out something new, and we can lead them to read. The characteristics of students at that level can be optimized by GIR activities. 
To get students engaged in reading is not an easy way. Reading should be enjoyable and joyful to attract students to start reading. As Alderson (2001, p. 28) states that reading as "an enjoyable, intense, private activity, from which much pleasure can be derived, and in which one can become totally absorbed". An interesting theme or topic will make the students curious about the content and the extensive reading program helps them starting to read unconsciously to find out the answer of their own questions about the text.

The researcher believes that the intrinsic motivation is the core motivation of reading. As Hirabe \& Feryok (2013, p. 89) say that the ability to self-regulate played more important roles than materials. It means that if they intrinsic motivation have awaken; the other motivation will increase too. So, in this research, the researcher was tried to find out the effect of extensive reading to their intrinsic motivation.

Vocabulary here refers to the word meaning. The importance of vocabulary is beyond doubt. Knowledge of word meanings is even assessed as a fundamental component of intelligence or general cognitive functioning. ER will affect the students' vocabulary, as Shanahan (2005, p. 25) states that "Reading can influence their vocabulary learning, and teachers should show care in the selection of these materials to ensure that they introduce useful words with sufficient context and illustration."

Vocabulary knowledge means the vocabulary that required for reading. The researcher uses Nation (1993) test for 1000 words of English to measure learners' written receptive vocabulary size in English.

Dorn \&, Soffos (2005, pp. 6-7) said that comprehension results from the mind's ability to make links and ask questions regarding the articular reading event. To comprehend, the reader must able to construct the meaning by recognizing words first as Prior (2006, p. 7) says: "Comprehending means having the ability to connect words and thoughts to knowledge already possessed."

From the statement above, we can conclude that reading and comprehension is a packet that should be mastered by readers to get the meaning from a text. Comprehension here focuses on practice and providing interesting and comprehensible texts. Teachers guide is used to help children understand a text.

Researcher believes that skimming, scanning, summarizing, and previewing are useful skill for beginners. The main activities in reading was divided into three; pre reading, during reading, and after reading. A small book is given to each student to write down a word and help them record their activities, so they can keep in focus and concentrate when reading. The GIR covers the explicit teaching comprehension, and will be used to explore it.

Graded reader is a book "contain few, if any, questions and exercises, and this is one way of distinguishing them from textbooks and un-simplified annotated "side readers" (Bamford, 1984, p. 218). The researcher mostly supply graded reader books level 2 which are suitable with their word level based on placement test. The book is about a narrative text. The feature in narrative text is able to produce visualization in the reader as a part of the reading process 
(Denis in Alderson, 2001, p. 64). Narrative text is entertaining and student will learn the feeling of the character or place described on the story.

\section{Research Methods}

\section{Research Design}

The research was quasi-experimental in nature. It used two experimental groups and one control group. There were four variables involved, i.e. GIR as the independent variable, the students' motivation, vocabulary knowledge, and reading comprehension ability as the dependent variables.

\section{Settings of the Study}

This research was conducted at SMPN 1 Bantarsari-Cilacap, Central Java. The research was held from November 2013 to January 2014.

\section{Population and Sample}

The population was 254 students of grade VIII, which consisted of seven classes. A sample of three classes was selected randomly. Based on Hsui's suggestion, the experimental groups should have schedule on the beginning or the ending of the weeks. Those are good days for GIR because starting and finishing the week with pleasure reading enhances the development of positive attitudes. So, the researcher chose VIII A (31 students) and VIII G (33 students) as the first and second experimental group.

Meanwhile for the control group the researcher chose VIII C (32 students). The control group was chosen based on the teacher's suggestion to the researcher. It was an active class with similar population to the experimental group.

\section{Procedure}

There were two groups which were given different treatment, those are: experimental groups and control group. The first experimental group was treated by the GIR variation 1; and GIR variation 2 for the second experimental group, while the control group will be taught by a conventional technique.

First step of the research was hold placement test to the experimental groups. The result of the test was used to decide graded reader book levels. The test material was taken from Nations test for first 1000 words of English.

The second step of the research was held pretest in all sample (experimental and control group) by using the same questions. This test aimed to know the students' position before the treatment started. Thus, also used as the basic data to specify the improvement after treatment. 
The third steps, the researcher arranged treatment to the experimental groups (GIR) and conventional technique for the control group; and the last steps was giving motivation questionnaire and posttest at the end of treatment for all classes.

The whole research activities can be seen in the following figure.

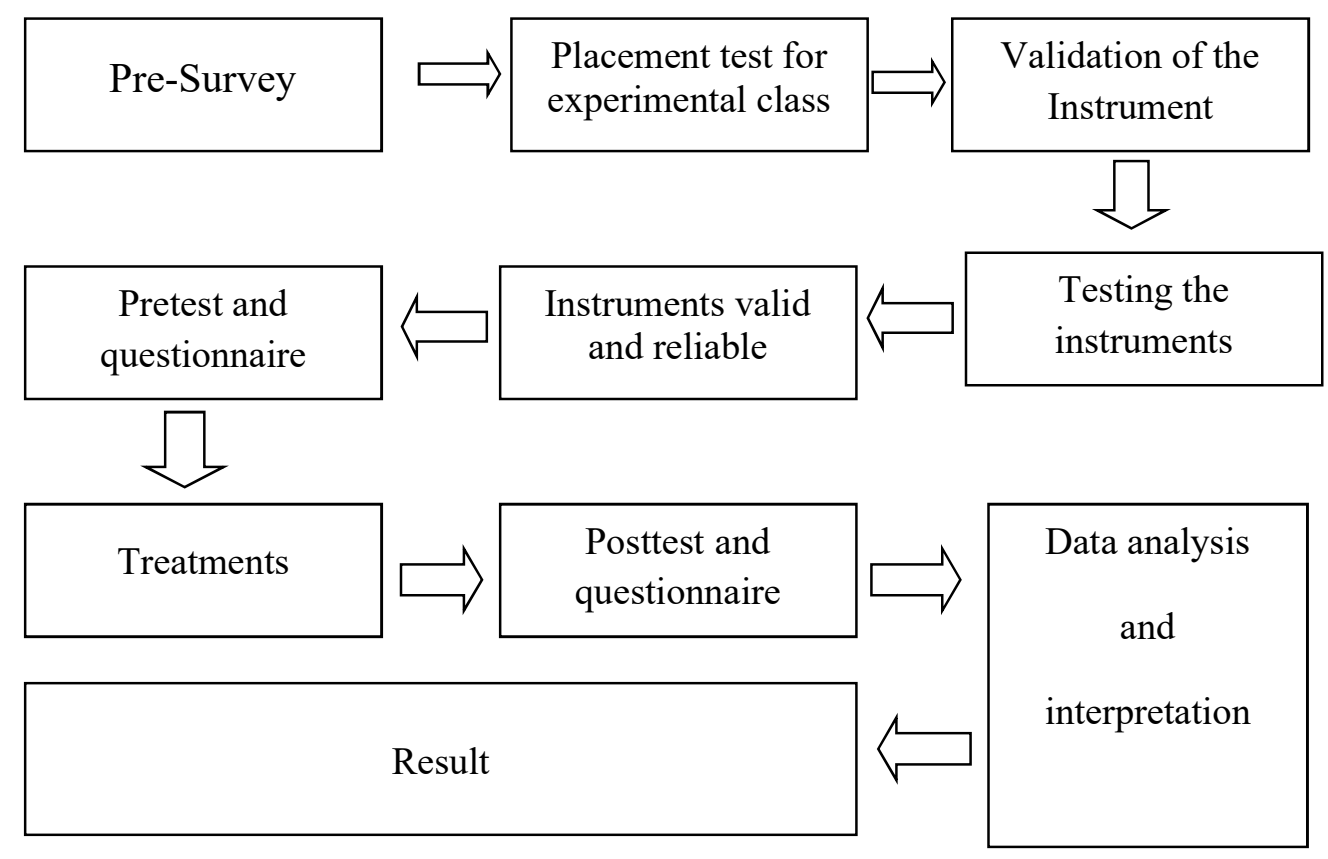

Figure 1. Research Activities

\section{Variables of the Research}

The independent variable in this research is GIR activity variation 1 and variation 2 . The dependent are the students' motivation, vocabulary knowledge, and reading comprehension ability.

The techniques used to collect the data were test and non-test instruments. To collect the data about vocabulary knowledge and reading comprehension, test instrument was used. While the non-test instrument (questionnaire) was used to find out the data about students' intrinsic motivation.

The questionnaire of intrinsic motivation consisted of eight questions. The students' answers were scored using Likert scale. There were four scales: very disagree; disagree; agree; and very agree.

The vocabulary knowledge and reading comprehension ability test instruments were in the form of multiple-choice tests. 


\section{Reliability of the Instruments}

Based on the counting, the reliability of the instrument is as follows: motivation reliability is 0.895 ; vocabulary knowledge pretest reliability is 0.940 ; vocabulary posttest reliability is 0.941 ; reading comprehension ability pretest is 0.941 ; and reading comprehension ability is 0.943 .

The data were analyzed by descriptive and inferential analysis. The descriptive analysis used here was mean, minimum score, maximum score, standard deviation of variance, and percentage of the students which has been categorized. To describe the effect of treatment, the researcher used the criterion based on mean ideal (Mi) and standard deviation ideal $(\mathrm{Si})$ by converse quantitative to qualitative five-scaled.

\begin{tabular}{cc}
\hline Interval motivation score & Criterion \\
\hline $81.25<\mathrm{X} \leq 100$ & Very High \\
$68.75<\mathrm{X} \leq 81.25$ & High \\
$56.25<\mathrm{X} \leq 68.75$ & Medium \\
$43.75<\mathrm{X} \leq 56.25$ & Low \\
$25 \leq \mathrm{X} \leq 43.72$ & Very low \\
\hline
\end{tabular}

Table 1. Criterion of Students' Motivation

The vocabulary data were taken by using Nations vocabulary, this test was designed to measure both first language and second language learners' written receptive vocabulary size in English. The data were true and false choices and the "don't know the meaning" as the other choices, and consists of 40 items.

The reading comprehension data was collected with multiple choice tests, consist of 20 items. The test materials consist of six reading text and eight reading competence. Both vocabulary knowledge and reading comprehension had the same maximum and minimum score.

The data of vocabulary knowledge and reading comprehension then categorized with the criterion on the table 2, and then grouped to the percentage of each category, which was: very high, high, middle, low, very low.

\begin{tabular}{cc}
\hline Interval Vocabulary Knowledge and Reading Comprehension Score & Criterion \\
\hline $75.01<\mathrm{X} \leq 100$ & Very High \\
$58.34<\mathrm{X} \leq 75.01$ & High \\
$41.67<\mathrm{X} \leq 58.34$ & Medium \\
$25.00<\mathrm{X} \leq 56.25$ & Low \\
$0.00 \leq \mathrm{X} \leq 25.00$ & Very low \\
\hline
\end{tabular}

Table 2. Criterion of Vocabulary Knowledge and Reading Comprehension

There were two activities in analyzing the quantitative data; testing assum testing hypothesis. 
The data before and after the treatment were analyzed by using Multivariate analysis. It used in this research because we use two variable factors; experiment and control group and three dependent variables; motivation, vocabulary knowledge, and reading comprehension skills. The researcher uses SPSS 16.0 for windows as a help to count the data.

The hypothesis of the testing assumption of covariance for normality of multivariate stated as follows.

$$
\begin{aligned}
& \mathrm{H}_{\mathrm{o}}=\text { The data covariance is equal } \\
& \mathrm{H}_{\mathrm{a}}=\text { The data covariance is } \\
& \text { different }
\end{aligned}
$$

If the significance $>0.05, \mathrm{H}_{0}$ is accepted (the data covariance are equal) and $\mathrm{H}_{0}$ was rejected if the significance $<0.05$ (the data covariance is different). The result of Box's test of equality of Covariance is presented in the table 3 below.

\begin{tabular}{lr}
\hline Box's M & 7.314 \\
\hline F & .581 \\
df1 & 12 \\
df2 & $4.166 \mathrm{E} 4$ \\
Sig. & .859 \\
\hline
\end{tabular}

Tests the null hypothesis that the observed covariance matrices of the dependent variables are equal across groups.

a. Design: Intercept + Kelas

Table 3. Box's Test of Equality of Covariance Matrices ${ }^{a}$

The table showed that the significance at the Box's test was .859. Since $p$-value was higher than covariance critical value, .859>0.05, the Ho was accepted. It means that the data covariance is equal.

The hypothesis of the testing assumption of variance for homogeneity of variance stated as follows.

$$
\begin{aligned}
\mathrm{H}_{\mathrm{o}}= & \text { The groups of the data } \\
& \text { variance are equal. } \\
\mathrm{H}_{\mathrm{a}}= & \begin{array}{l}
\text { The groups of the data } \\
\text { variance are different. }
\end{array}
\end{aligned}
$$

If the significance $>0.05, \mathrm{H}_{0}$ was accepted (the data variance is equal) and $\mathrm{H}_{0}$ was rejected if the significance $<0.05$ (the data variance is different). The result of Levene's test of equality of variance is presented in the table 4 below. 


\begin{tabular}{lrrrr}
\hline & F & df1 & df2 & Sig. \\
\hline Motivasipre & .181 & 2 & 93 & .834 \\
Vocabspre & .026 & 2 & 93 & .974 \\
RCpre & 1.738 & 2 & 93 & .182 \\
\hline
\end{tabular}

Tests the null hypothesis that the error variance of the dependent variable is equal across groups.

a. Design: Intercept + Kelas

Table 4. Levene's Test of Equality of Error Variances ${ }^{a}$

The table shows that the significance at the Levene's test was .834 for motivation, .974 for vocabulary knowledge and .182 for reading comprehension ability. Since p-value is higher than critical value, $(\mathrm{p}>0.05)$, H0 was accepted. It means that the group of the data on motivation, vocabulary knowledge and reading comprehension ability was equal on variance among the three classes before treatment. In other words, the three classes were in the same level of all variance.

To test the affectivity each learning models to each dependent variable (motivation, vocabulary knowledge, and reading comprehension skills) we use one sample t-test.

\section{One Sample t-test}

To find out the effect of extensive reading, GIR variation 1, GIR variation 2 and conventional technique to each variables the researcher make a criteria affectivity. The standard of effectiveness on motivation is 68.75 . Whereas vocabulary knowledge and reading comprehension skills said effective if they reach 58.34. All criteria were based on high criterion of mean ideal (Mi) and Standard deviation ideal $(\mathrm{Si})$ decided by the researcher as mentioned before.

By assuming that the first group GIR variation 1; the second group is GIR variation 2; and the third group as conventional; then motivation as the first variable; vocabulary knowledge as the second variable; and the reading comprehension skills as the third variable; there are 9 hypotheses to find out the effect of each variables.

To answer the hypotheses of the research, the researcher used one sample t-test. The researcher used SPSS 16.0 for windows to help counting the data.

\section{Multivariate Analysis}

The multivariate was used to find out the effectiveness between GIR and a conventional technique on students' motivation, vocabulary knowledge and reading comprehension ability. Below the hypothesis tested.

$\mathrm{H}_{010}$ : The GIR is not more effective than a conventional method in the students' motivations, vocabulary knowledge and reading comprehension skill. 
$\mathrm{H}_{\mathrm{a} 10}$ : The GIR is more effective than a conventional method in the students' motivations, vocabulary knowledge and reading comprehension skill..

Then, the second hypotheses tested, with the hypothesis as follows.

$\mathrm{H}_{011}$ : There is no significant difference on the effectiveness between GIR variation 1 and GIR variation 2 on motivation, vocabulary knowledge, and reading comprehension skills.

$\mathrm{H}_{\mathrm{a} 11}$ : There is significant difference on the effectiveness between GIR variation 1 and GIR variation 2 on motivation, vocabulary knowledge, and reading comprehension skills.

The researcher applied SPSS 16.0 for windows by Contrast Helmert with significance 5\% to count the data. When the significance $(p)<0.05$, it means that $\mathrm{H}_{0}$ is rejected.

\section{Univariate Test}

According to multivariate contrast Helmert There was significance difference between affectivity of the conventional and GIR on motivation, vocabulary knowledge, and reading comprehension skills, the post hoc is done to find out which one is more affective, control group or experiment group, Tukey is used with significance 0.05 . The criterions are:

a) If the trustworthiness Tukey is 0 , it means the mean of the population compared had no difference significantly.

b) If the trustworthiness Tukey is not 0 and the edge of the interval is negative (-), it means that mean of the second group (j) is higher than mean of the first group (i).

c) If the trustworthiness Tukey is not 0 and the edge of the interval is positive $(+)$, it means that mean of the first group (i) is higher than mean of the second group $(j)$.

The post hoc is done by SPSS 16.0 for windows. If significance $(p)<0.05$ it means there are differences between the compared group. By seeing Mean Difference, we can see the better one. If Mean Difference positive (+) it means that the first group is better than the second group. In other words, if Mean Difference negative (-), the second group is better than the first group.

\section{Findings and Discussion}

\section{Placement Test}

In arranging a syllabi and goal, the researcher held a placement test first. Based on the placement test, the researcher decided to prepare the graded readers books mostly with around 800 vocabularies on it. 


\section{Preliminary Research}

This study used a questionnaire and a test of students' competence. The questionnaire was used to find out the students' motivation in reading, whereas the test was used to measure the students' vocabulary knowledge and the students reading comprehension ability.

The result of the preliminary test was analyzed by using Manova, and the result has fulfilled the normality and homogeneity of Multivariate. It means that all classes have the same condition before the treatment.

\section{Students’Motivation}

The questionnaire of students' motivation in reading consists of 8 items. The researcher measures their intrinsic motivation before and after the treatment both on experimental and control groups. Here is the description of students' motivation on reading before and after treatment.

\begin{tabular}{lrrrrrr}
\hline \multirow{2}{*}{ Motivation } & \multicolumn{2}{c}{ GIR 1 } & \multicolumn{2}{c}{ GIR 2 } & \multicolumn{2}{c}{ Control } \\
\cline { 2 - 7 } & \multicolumn{1}{c}{ Before } & \multicolumn{1}{c}{ After } & \multicolumn{1}{c}{ Before } & \multicolumn{1}{c}{ After } & Before & \multicolumn{1}{c}{ After } \\
\hline Mean & 62.30 & 72.986 & 59.661 & 74.915 & 59.863 & 66.4062 \\
Minimum score theoretic & 25 & 25 & 25 & 25 & 25 & 25 \\
Minimum score & 50 & 62.5 & 43.75 & 62.5 & 50 & 56.25 \\
Maximum score & 100 & 100 & 100 & 100 & 100 & 100 \\
theoretic & 71.88 & 81.25 & 75 & 87.5 & 71.88 & 78.13 \\
Maximum score & 33.17 & 30.3 & 45.999 & 38.736 & 36.619 & 35.287 \\
Variance & 5.759 & 5.504 & 6.782 & 6.223 & 6.050 & 5.940 \\
Std. Deviation & &
\end{tabular}

Table 5. Description of Students' Motivation on Reading

Table 5 shows that the mean score of students' motivations before treatment on GIR variation 1 is 62.30 . It belongs to the medium interval score. The GIR variation 2 is 59.66 , belong to the interval medium score; and the control class 59.86 it is also belong to the medium interval class.

The mean of students' motivation in reading after treatment on the GIR variation 1 class is 72.98 it belongs to the high interval score. The GIR variation 2 is 74.91 belong to the high interval score, and the control group is 66.40 and still in the medium interval class. It shows that all the class has increase on their reading motivation compared with the score before treatment.

Frequencies and percentages students on each criterion were counted as the range made before. The distribution frequencies and percentages students' motivation on reading before and after treatment is presented below. 
Motivation

\begin{tabular}{lccccccccccccc}
\hline & \multicolumn{3}{c}{ ER-GIR 1 $(\mathrm{n}=31)$} & \multicolumn{3}{c}{ ER-GIR 2 $(\mathrm{n}=33)$} & \multicolumn{3}{c}{ Control $(\mathrm{n}=32)$} \\
\cline { 2 - 12 } Criterion & \multicolumn{3}{c}{ Before } & \multicolumn{2}{c}{ After } & \multicolumn{2}{c}{ Before } & After & \multicolumn{1}{c}{ Before } & \multicolumn{2}{c}{ After } \\
\cline { 2 - 14 } Very & $\mathrm{f}$ & $\%$ & $\mathrm{f}$ & $\%$ & $\mathrm{f}$ & $\%$ & $\mathrm{f}$ & $\%$ & $\mathrm{f}$ & $\%$ & $\mathrm{f}$ & $\%$ \\
High & 0 & 0.0 & 0 & 0.0 & 0 & 0.0 & 7 & 21.2 & 0 & 0.0 & 0 & 0.0 \\
High & 3 & 9.7 & 21 & 67.7 & 1 & 3.0 & 22 & 66.7 & 1 & 3.1 & 8 & 25.0 \\
Medium & 21 & 67.7 & 10 & 32.3 & 21 & 63.6 & 4 & 12.1 & 21 & 65.6 & 22 & 68.8 \\
Low & 7 & 22.6 & 0 & 0.0 & 11 & 33.3 & 0 & 0.0 & 10 & 31.3 & 2 & 6.3 \\
Very Low & 0 & 0.0 & 0 & 0.0 & 0 & 0.0 & 0 & 0.0 & 0 & 0.0 & 0 & 0.0 \\
\hline \hline
\end{tabular}

Table 6 above shows that before treatment the students' motivation on all class has similar position. There is no student belong to very low motivation on reading, and most students stay at medium motivation. When it is compared to the result after the treatment, it can be seen that their motivation increased on reading. The first group, GIR variation 1 shows that the students who have low motivation before treatment is seven and it became zero after the treatment. They are 21 students $(67.7 \%)$ stay on medium motivation before the treatment, and it is decreased to $10(32.2 \%)$. The students' motivation who stays on high criterion increased from $3(9.68 \%)$ to $21(67.7 \%)$ after the treatment. In short, the motivation on the first class increased. There were only two intervals of motivation in GIR variation 1 class, medium and high. Most of the students $(67.7 \%)$ had high motivation after treatment.

The second group of treatment had the similar improvement. Before treatment, there were 11 students $(33.3 \%)$ who stayed on low motivation. After the treatment, the class motivation increased. There was no student staying on low motivation, 4 students $(12.1 \%)$ had medium motivation and there was 22 students $(66.7 \%)$ on high motivation, and 7 students $(21.2 \%)$ had very high motivation after the treatment.

The control group, conventional method also increased after the treatment, but two students $(6.25 \%)$ were left on low motivation level. 22 students $(68.8 \%)$ stayed on medium motivation level, and only 8 students ( $25 \%$ )were categorized high motivation.

The effectiveness criterion has been targeted for motivation which is more than 68.75 of interval score or at least including in the high category. From table 16 we can see that GIR variation 1 class increased from $9.68 \%$ to $67.7 \%$, on GIR variation 2 increased from $3.03 \%$ to $87.9 \%$ and the control group increased from $3.13 \%$ to $25 \%$. The data describes clearly that the highest progress on students' motivation is GIR variation 2 on the experimental group, and the lowest are the control group. 


\section{Students' Vocabulary Knowledge}

The Nation test item was used on this research. There were 40 items of true and false questions. Besides of those choices, there was another choice allowed to answer "I don't know" choice, which make the test shorter and saved time. At first, if they chose it, it was considered as correct score because it showed that the students carefully considered the options. But, on the result, the "I don't know" was not their choice.

The researcher measured their vocabulary knowledge before and after the treatment both on experimental and control groups. Here are the data.

\begin{tabular}{lrrrrrr}
\hline \multirow{2}{*}{ Vocabulary Knowledge } & \multicolumn{2}{c}{ GIR 1 } & \multicolumn{2}{c}{ GIR 2 } & \multicolumn{2}{c}{ Control } \\
\cline { 2 - 7 } & \multicolumn{1}{c}{ Before } & \multicolumn{1}{l}{ After } & \multicolumn{1}{c}{ Before } & \multicolumn{1}{c}{ After } & Before & After \\
\hline Mean & 56.371 & 74.6774 & 59.6212 & 71.5909 & 61.875 & 64.6875 \\
\hline Minimum score & 0 & 0 & 0 & 0 & 0 & 0 \\
theoretic & 35 & 55 & 40 & 50 & 42.5 & 50 \\
Minimum score & 100 & 100 & 100 & 100 & 100 & 100 \\
Maximum score & 72.5 & 95 & 85 & 85 & 80 & 80 \\
theoretic & 71.599 & 114.059 & 73.875 & 113.601 & 66.129 & 79.738 \\
Maximum Score & 8.4617 & 10.6799 & 8.59508 & 10.6584 & 8.13198 & 8.92961 \\
Variance & Std. Deviation &
\end{tabular}

Table 7. Description of Students' Vocabulary Knowledge

Table 7 shows that the mean score of students' vocabulary knowledge before treatment on GIR variation 1 class is 56.37 and it belongs to the medium interval. GIR variation 2 class before treatment is 59.62. It belongs to the interval medium. The Vocabulary knowledge for the control class is 61.87 , and it belongs to interval medium.

The average of students' vocabulary knowledge in reading after treatment on the GIR variation 1 class is 74.67 . It belongs to high interval. The GIR variation 2 class is 71.59 belong to high criterion and the control class 64.68 and still belong to medium criterion. It increase only 2.81, whereas the experimental class increase more than 10 (GIR variation 1 is 18.3 and GIR variation 2 is 11.97).

Frequencies and percentages students on each criterion were counted as the range made before. The distribution frequencies and percentages students' vocabulary knowledge before and after treatment served below. 
Lingua Pedagogia

Vol.2, No.1, March 2020

\begin{tabular}{lcccccccccccc}
\hline & \multicolumn{3}{c}{ ER-GIR 1 $(\mathrm{n}=31)$} & \multicolumn{3}{c}{ ER-GIR 2 $(\mathrm{n}=33)$} & \multicolumn{3}{c}{ Control $(\mathrm{n}=32)$} \\
\cline { 2 - 13 } Criterion & \multicolumn{2}{c}{ Before } & \multicolumn{2}{c}{ After } & \multicolumn{2}{c}{ Before } & \multicolumn{2}{c}{ After } & \multicolumn{2}{c}{ Before } & After \\
\cline { 2 - 14 } Very High & $\mathrm{f}$ & $\%$ & $\mathrm{f}$ & $\%$ & $\mathrm{f}$ & $\%$ & $\mathrm{f}$ & $\%$ & $\mathrm{f}$ & $\%$ & $\mathrm{f}$ & $\%$ \\
High & 0.0 & 15 & 48.4 & 1 & 3.0 & 11 & 33.3 & 1 & 3.1 & 11 & 34.4 \\
Medium & 11 & 35.5 & 12 & 38.7 & 19 & 57.6 & 18 & 54.5 & 19 & 59.4 & 17 & 53.1 \\
Low & 51.6 & 4 & 12.9 & 12 & 36.4 & 4 & 12.1 & 12 & 37.5 & 4 & 12.5 \\
\hline Very Low & 4 & 12.9 & 0 & 0.0 & 1 & 3.0 & 0 & 0.0 & 0 & 0.0 & 0 & 0.0 \\
\hline \hline
\end{tabular}

The table 8 above shows that before treatment no one of the students belongs to very low interval class; in experimental group, there are 4 students $(12.9 \%)$ on GIR variation 1 and 1 student $(3 \%)$ of GIR variation 2 . After the treatment, no one left on low vocabulary knowledge level.

As 58.34 is the point of showing the effectiveness, both experimental and control show that there are improvements in their vocabulary knowledge after the treatment. The highest improvement was on the experimental group, GIR variation 1 who has $51.6 \%$, and the lowest improvement was on the control group, $6.3 \%$.

\section{Students' Reading Comprehension Ability}

The test of students' reading comprehension skills consisted of 20 items. It was multiple choices with seven texts on the pretest and posttest. Here are the results.

\begin{tabular}{lrrrrrr}
\hline \multirow{2}{*}{\begin{tabular}{l} 
Reading Comprehension \\
\multicolumn{1}{c}{ Ability }
\end{tabular}} & \multicolumn{2}{c}{ GIR 1 } & \multicolumn{2}{c}{ GIR 2 } & \multicolumn{2}{c}{ Control } \\
\cline { 2 - 7 } & \multicolumn{1}{c}{ Before } & \multicolumn{1}{c}{ After } & Before & After & Before & After \\
\hline Mean & 56.29 & 60 & 56.0606 & 66.0606 & 50.7812 & 55.625 \\
Minimum score theoretic & 0 & 0 & 0 & 0 & 0 & 0 \\
Minimum score & 40 & 40 & 40 & 50 & 35 & 35 \\
Maximum score & 100 & 100 & 100 & 100 & 100 & 100 \\
theoretic & 75 & 80 & 75 & 85 & 75 & 70 \\
Maximum score & 69.946 & 123.333 & 79.309 & 99.621 & 125.983 & 89.919 \\
Variance & 8.3634 & 11.1056 & 8.90554 & 9.98104 & 11.2242 & 9.48258 \\
Std. Deviation & & &
\end{tabular}

Table 9. Description of Students' Reading Comprehension Ability

Table 9 shows that the average score of students' reading comprehension skills before treatment on GIR variation 1 class is 56.29. It belongs to medium interval. The GIR Variation 2 class is 56.06 . It belongs to medium interval score, and the control class 50.78 belongs to medium interval score. 
The average of students' motivation in reading after treatment on the GIR Variation 1 class is 60. It belongs to high interval score. The GIR Variation 2 is 66.06 belong to high interval score, and the control class 55.63 and belong to medium interval.

Although it seems that there is no difference between experimental and control group, by seeing on the maximum score reached, there is improvement on the experimental group. GIR variation 1 maximum score increase from 75 before treatment to 80 after the treatment, and 75 to 85 for GIR variation 2, whereas the control group decreases from 75 to 70 .

Frequencies and percentages students on each criterion of reading comprehension skills were counted as the range made before. Here is the brief description of distribution frequencies and percentages students' reading comprehension skills before and after treatment.

\begin{tabular}{|c|c|c|c|c|c|c|c|c|c|c|c|c|}
\hline \multirow{3}{*}{ Criterion } & \multicolumn{4}{|c|}{ ER-GIR $1(n=31)$} & \multicolumn{4}{|c|}{ ER-GIR $2(\mathrm{n}=33)$} & \multicolumn{4}{|c|}{ Control $(n=32)$} \\
\hline & \multicolumn{2}{|c|}{ Before } & \multicolumn{2}{|c|}{ After } & \multicolumn{2}{|c|}{ Before } & \multicolumn{2}{|c|}{ After } & \multicolumn{2}{|c|}{ Before } & \multicolumn{2}{|c|}{ After } \\
\hline & $\mathrm{f}$ & $\%$ & $\mathrm{f}$ & $\%$ & $\mathrm{f}$ & $\%$ & $\mathrm{f}$ & $\%$ & $\mathrm{f}$ & $\%$ & $f$ & $\%$ \\
\hline $\begin{array}{l}\text { Very } \\
\text { High }\end{array}$ & 0 & 0.0 & 4 & 12.9 & 0 & 0.0 & 4 & 12.1 & 0 & 0.0 & 0 & 0.0 \\
\hline High & 13 & 41.9 & 16 & 51.6 & 14 & 42.4 & 21 & 63.6 & 7 & 21.9 & 19 & 59.4 \\
\hline Medium & 17 & 54.8 & 9 & 29.0 & 17 & 51.5 & 8 & 24.2 & 16 & 50.0 & 12 & 37.5 \\
\hline Low & 1 & 3.2 & 2 & 6.5 & 2 & 6.1 & 0 & 0.0 & 9 & 28.1 & 1 & 3.1 \\
\hline $\begin{array}{l}\text { Very } \\
\text { Low }\end{array}$ & 0 & 0.0 & 0 & 0.0 & 0 & 0.0 & 0 & 0.0 & 0 & 0.0 & 0 & 0.0 \\
\hline
\end{tabular}

Table 10. Distribution Frequencies and Percentages of Students' Reading Comprehension Ability

Table 10 above shows that there is no students stay in the very low criterion of reading comprehension before treatment. Most of the students stay on the medium and high criterion, and no body of all group have very high criterion on reading comprehension.

When the indicator of successful treatment is a test result, at least belong to high interval class or more, it means that there are $41.9 \%$ students of first group, GIR variation 1 who have high ability on reading comprehension skills before the treatment. After the treatment, there are $64.6 \%$ of the students belong to the high and very high interval class of reading comprehension skills.

The data of the second group, GIR variation 2 shows that there are $42.4 \%$ students stay on the high and above criterion before the treatment. It increases after the treatment, and has $75.7 \%$ students who belong to the high and very high criterion.

The last group, on the control group there were 7 students $(21.5 \%)$ stay on high criterion and above before treatment, became 12 students (37.5\%) after the treatment stay at high criterion. In this group, the students' reading comprehension ability before and after the treatment was on the same criterion, high criterion. There is no student who are able to reach very high criterion as the results. 
From table 11 we can see that the effective criterion has been targeted for reading comprehension is more than $58.34 \%$, in high and very high criterion. It can be seen that the GIR Variation 1 class increased $22.6 \%$, on GIR Variation 2 increased $33.2 \%$, and the control group increased $16.5 \%$. The data describe clearly the highest progress on students' reading comprehension ability are the experimental group. But there were two students left on the low criterion at the first experimental group.

Table 11 below shows the homogeneity of the group which is similar or different with the other group. It describes about mean scores reached in each group and variable.

Tukey HSD

\begin{tabular}{|c|c|c|c|c|}
\hline & & \multirow{2}{*}{$\mathrm{N}$} & \multicolumn{2}{|c|}{ Subset } \\
\hline & & & 1 & 2 \\
\hline \multirow{4}{*}{ Motivation } & Conventional & 32 & 66.4084 & \\
\hline & GIR variation 1 & 31 & & 72.9868 \\
\hline & GIR variation 2 & 33 & & 74.9152 \\
\hline & Sig. & & 1 & 0.395 \\
\hline \multirow{4}{*}{$\begin{array}{l}\text { Vocabulary } \\
\text { knowledge }\end{array}$} & Conventional & 32 & 64.6875 & \\
\hline & GIR variation 2 & 33 & & 71.5909 \\
\hline & GIR variation 1 & 31 & & 74.6774 \\
\hline & Sig. & & 1 & 0.445 \\
\hline \multirow{4}{*}{$\begin{array}{c}\text { Reading } \\
\text { Comprehension } \\
\text { Ability }\end{array}$} & Conventional & 32 & 55.625 & \\
\hline & GIR variation 1 & 31 & 60 & 60 \\
\hline & GIR variation 2 & 33 & & 66.0606 \\
\hline & Sig. & & 0.205 & 0.051 \\
\hline
\end{tabular}

The data shows us that means of the motivation, vocabulary knowledge, and reading comprehension ability group GIR variation 1 and GIR variation 2 are at the same subset. It means that the groups have no significant differences on all variables. 


\section{Conclusion and Recommendation}

\section{Conclusion}

Based on the data analysis and discussion, the researcher concludes several items:

1. The GIR has a significant effect on the students' motivation. It is indicated by $t_{\text {result }}=$ 4.285 of GIR 1 and $t_{\text {result }}=5.690$ of GIR 2. which are bigger than $t_{\text {table }}$ of both class $(2.042$ for GIR variation 1 and 2.036 for GIR variation 2).

2. The GIR has a significant effect on the students' vocabulary knowledge. It is indicated by $t_{\text {result }}=8.517$ of GIR 1 and $t_{\text {result }}=7.142$ of GIR 2 .which are bigger than $t_{\text {table }}$ of both class (2.042 for GIR variation 1 and 2.036 for GIR variation 2).

3. The GIR variation 2 has a significant effect on the students' reading comprehension ability. It is indicated by $t_{\text {result }}=4.444$ of GIR 2 . which are more than $t_{\text {table }}(2.036)$ but GIR variation 1 has no significant effect on the students' reading comprehension ability, indicated by $t_{\text {result }}=0.837$ of GIR 1 .which are less than $t_{\text {table }}(2.042)$

4. The GIR is more effective than conventional method in the students' motivation, indicated by (p) .000 for GIR variation 1 and variation 2 which are less than sig-value 0.05 .

5. The GIR is more effective than conventional method on improving the students' vocabulary knowledge indicated by $(p) .000$ for GIR variation 1 and .019 for GIR variation 2 which are less than sig-value 0.05 .

6. The GIR is more effective than a conventional method on improving the students' reading comprehension ability when GIR variation 2 is used. It is indicated by $(p) .000$, but it is as effective as conventional method in GIR variation 1, indicated by (p) .210 which is more than sig-value 0.05 .

7. There is no difference affectivity between GIR variation 1 and GIR variation 2 on improving motivation, Vocabulary knowledge, and reading comprehension ability.

\section{Recommendation}

Based on the conclusion and implication and seeing the limitation of the research, the researcher suggests several items as follows:

1. It is suggested to an English teacher who will use GIR in teaching reading to have a placement test first to decide the graded reader books given, so the materials will be suitable for the students' level.

2. It is suggested to use GIR continuously, not only in a short term. When the activity is only in short term, the vocabulary the students got in GIR, will be lost.

3. To build the students' reading habit, it is suggested to integrate the extensive reading activities at school curriculum. 


\section{References}

Alderson, J. C. (2001). Assessing Reading. Cambridge University Press.

Bamford, J. (1984). Extensive reading by means of graded readers. Reading in a Foreign Language, 2(2).

Day, R. R., Bamford, J., Renandya, W. A., Jacobs, G. M., \& Yu, V. W.-S. (1998). Extensive reading in the second language classroom. RELC Journal, 29(2), 187-191.

de Burgh-Hirabe, R., \& Feryok, A. (2013). A model of motivation for extensive reading in Japanese as a foreign language. Reading in a Foreign Language, 25(1), 72-93.

Dorn, L. J., \& Soffos, C. (2005). Teaching for deep comprehension: A reading workshop approach. Stenhouse Publishers.

Hsui, V. Y. (2000). Guided independent reading (GIR): a programme to nurture lifelong readers. Teaching and Learning, 20(2), 31-39.

Krashen, S. D. (1981). Second language acquisition and second language learning. Pergamon Press Inc.

Mikulecky, B. S., \& Jeffries, L. (1996). Reading power: Reading for pleasure, comprehension skills, thinking skills, reading faster. Reading, Mass: Addison-Wesley.

Nation, P. (1993). Using dictionaries to estimate vocabulary size: Essential, but rarely followed, procedures. Language Testing, 10(1), 27-40.

https://doi.org/10.1177\%2F026553229301000102

Nuttall, C. (1996). Teaching reading skills in a foreign language. Heinemann.

Prior, J. O. (2006). Nonfiction Comprehension Test Practice Gr. 4. Shell Education.

Shanahan, T. (2005). The National Reading Panel Report: Practical Advice for Teachers. Learning Point Associates.

\section{Profile}

Rochana Purba Nurfauzi was born in Cilacap, March, 13, 1981. He studied his elementary and junior high school in Cilacap, and continued his senior high school at Purwokerto. He continued his undergraduate school on Muhammadiyah University of Purwokerto (UMP), and achieved his degree of English teacher and education on 2003.

He taught in SMP PGRI 23 Bantarsari-Cilacap after his graduation (2003-2008), and then SMPN 1 Bantarsari since 2008-now. On 2012 he got scholarship to continue his study in applied linguistics of UNY and finished it on 2014. 